Journal of Mobile Communication 4 (3): 54-59, 2010

ISSN: 1990-794X

(C) Medwell Journals, 2010

\title{
Bandwidth Enhancement of Micro-Strip Patch Antenna
}

\author{
Hatem H. Abbas and Jabir S. Aziz \\ Department of Electronics and Communications Engineering, \\ College of Engineering, Nahrain University, Baghdad, Iraq
}

\begin{abstract}
The micro-strip patch in its pure form cannot satisfy the bandwidth requirements for most wireless communication systems. The general philosophy of most of the bandwidth enhancement techniques is to add one or more resonant structures to the micro-strip patch configuration. These additional elements may be in the form of slots or other patches. This study introduces, the design and analysis of bandwidth enhancements for a micro-strip patch antenna using different slots configurations. The results of this research show that an enhancement of about 5 times of the original bandwidth can be achieved by using $>1$ slot with proper positions selection.
\end{abstract}

Key words: Micro-strip antenna, bandwidth enhancement, slotted micro-strip antenna, light weight, mobile communication, Iraq

\section{INTRODUCTION}

Micro-strip antennas have been studied extensively because of the attractive advantages of low profile, ease of integration with active devises, low cost of production and light weight. Because of these merits, forms of the micro-strip patch antenna have been utilized in many applications such as in mobile communication base stations, space-borne satellite communication systems and even mobile communication handset terminals.

Despite these features, micro-strip patch antennas suffer from several inherent disadvantages of this technology in its pure form namely, they have small bandwidth and relatively poor radiation efficiency resulting from surface wave excitation and conductor and dielectric losses. Also to accurately predict, the performance of this form of radiator in particular, its input impedance nature, typically a full-wave computationally intensive numerical analysis is required (Xiao et al., 2006; Yang et al., 2001; Godara, 2002).

In order to improve the bandwidth characteristics of micro-strip antenna, different techniques have been proposed such as using stacked patches, slot coupling and parasitic patches on the same plane (Yu and Zhang, 2003).

A general law for antennas states that the lowest achievable quality factor of an antenna is inversely related to the antenna volume. This implies that the absolute bandwidth increases with increasing patch substrate height $\left(h / \lambda_{0}>0.1\right)$ since, the bandwidth is in inverse proportion to the quality factor. However, this technique introduces various problems. A thicker substrate will support surface waves which will deteriorate the radiation pattern as well as reduce the radiation efficiency.

Also, problems with the feeding technique of the antenna appear. The patch width has similar influence on the bandwidth like the substrate thickness. This comes from the fact that by increasing one of these parameters the volume of the antenna is increased.

Another important substrate parameter that influences the bandwidth is the permittivity. The bandwidth of a patch antenna increases with decreasing substrate permittivity (Bahl and Bhartia, 1980). By using low dielectric constant and thick substrate $\left(\mathrm{h} / \mathrm{h}_{\mathrm{O}}>0.1\right)$, the bandwidth can be reached $10 \%$.

Another technique for improving the bandwidth is the parasitic technique. There are two configurations of the parasitic geometry: the coplanar geometry and the stacked geometry. The coplanar geometry consist of many patches incorporate coplanar on the dielectric substrate and they are coupled to the main patch (only one patch has been excited). For stacked geometry, the patch radiators are employed one above the other with intervening dielectric layers. This allows two or more resonant patches to share a common aperture area. The stacked patch configuration has the following advantages:

- It does not increase the surface area of the element

- It can be used in array configurations without the

Corresponding Author: Hatem H. Abbas, Department of Electronics and Communications Engineering, College of Engineering, Nahrain University, Baghdad, Iraq 
danger of creating grating lobes. Its radiation patterns remain relatively constant over the operating frequency band

The drawbacks of stacked patch configuration are:

- It has a large number of parameters which make the design and optimization process is very complex

- It requires $>1$ substrate layer to support the patches

Applications of micro-strip antenna in present day communication systems require smaller antenna size in order to meet the miniaturization requirements of radio-frequency RF units (Xiao et al., 2006). This study introduces the design and analysis of different (regular and irregular) slots coupling configurations of micro-strip patch antenna and their effects on the bandwidth performance.

\section{MATERIALS AND METHODS}

Design considerations of the proposed antennas: The transmission line model can be considered for the calculations of the rectangular micro-strip patch antenna length.

The length (L) should be slightly $<\lambda / 2$ where $\lambda$ is the wavelength in the dielectric medium and it is equal to:

Where:

$$
\frac{\lambda_{0}}{\sqrt{\varepsilon_{\theta}}}
$$

$\lambda_{0}=$ The wavelength in free space

$\varepsilon_{\theta}=$ The effective dielectric constant (Kumar and Ray, 2003)

$\varepsilon_{\theta}$ is slightly $<\varepsilon_{Y}$ and that's because the fringing fields around the periphery of the patch are not confined in the dielectric substrate but are also spread in the air as shown in Fig. 1 and it can be approximately calculated as (Kumar and Ray, 2003; Grag et al., 2001):

Where:

$$
\varepsilon_{\theta}=\frac{\varepsilon_{\Upsilon}+1}{2}+\frac{\varepsilon_{\Upsilon}-1}{2}\left(\frac{1}{\sqrt{1+\frac{10 \mathrm{~h}}{\mathrm{~W}}}}\right)
$$

$\mathrm{h}=$ The patch substrate height

The radiation edge (W) is usually chosen such that it lies within the range $\mathrm{L}<\mathrm{W}<2 \mathrm{~L}$ for the efficient radiation, the ratio $\mathrm{W} / \mathrm{L}=1.5$ gives good

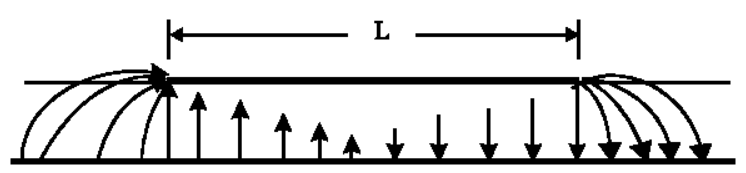

Fig. 1: E-field distribution for rectangular micro-strip antenna showing the fringing field

performance according to the side lobes appearance (Mohammad et al., 2006). The effective length for rectangular micro-strip antenna which caused by fringing effect is measured to be:

$$
\mathrm{L}_{\theta}=\mathrm{L}+\Delta 1
$$

where, $\Delta 1$ is the extension along the length and it is calculated as (Mohammad et al., 2006):

$$
\Delta \mathrm{l}=0.412 \mathrm{~h} \frac{\left(\varepsilon_{\theta}+0.3\right)\left(\frac{\mathrm{W}}{\mathrm{h}}+0.264\right)}{\left(\varepsilon_{\theta}+0.258\right)\left(\frac{\mathrm{W}}{\mathrm{h}}+0.813\right)}
$$

and then the effective length for the $\mathrm{TM}_{\mathrm{mn}}$ mode could be calculated from (Kumar and Ray, 2003):

$$
\mathrm{L}_{\theta}=\frac{\lambda_{0}}{2 \sqrt{\varepsilon_{\theta}}}=\frac{\mathrm{C}}{\mathrm{f}_{\mathrm{o}} \sqrt{\varepsilon_{0}}}
$$

The resonance frequency for the $\mathrm{TM}_{\mathrm{mm}}$ mode could be calculated from:

$$
\mathrm{f}_{\mathrm{o}}=\frac{\mathrm{C}}{2 \sqrt{\varepsilon_{\mathrm{r}}}}\left[\left(\frac{\mathrm{m}}{\mathrm{L}}\right)^{2}+\left(\frac{\mathrm{n}}{\mathrm{W}}\right)^{2}\right]
$$

Where $\varepsilon_{\Upsilon}$ is the relative permittivity. Assuming that:

- The required resonance frequency is $1.23 \mathrm{GHz}$

- $\mathrm{h} / \lambda_{0}$ is $1.6 \%$

- Relative permittivity $\left(\varepsilon_{\mathrm{r}}\right)$ is 2.62

For this assumptions and according to the above analysis, the patch dimensions of $76 \times 121.125 \mathrm{~mm}$ (LW) can be printed on a ground substrate of thickness (h) $4 \mathrm{~mm}(\sim 1.6 \%$ of the working wavelength) and size $30.4 \times 45.6 \mathrm{~cm}$ with good impedance matching which can be achieved by chosen a proper feed position.

The normalized patterns in the E-plane ( $\mathrm{E}_{\theta}$ in $\Phi=0^{\circ}$ plane) and the $\mathrm{H}$-plane ( $\mathrm{E}_{\Phi}$ in $\Phi=90^{\circ}$ plane) are given by Hammer et al. (1979): 


$$
E_{\theta}=\frac{j \cdot k \cdot \exp (-j k r)}{2 \pi r}\left[E_{x} \cdot \cos \phi+E_{y} \cdot \sin \phi\right]
$$

and

$$
E_{\varphi}=\frac{j \cdot k \cdot \exp (-j k r)}{2 \pi \Upsilon}\left[-E_{x} \cdot \sin \phi \cdot \cos \theta+E_{y} \cdot \cos \phi \cdot \cos \theta\right]
$$

Where:

$$
\mathrm{k}=\frac{2 \pi}{\lambda_{0}}
$$

Design and simulation of the proposed antenna: This study propose and design certain configuration to enhance the bandwidth without increasing the antenna size by using thin substrate (about $1.6 \%$ of the working wavelength), the design will be based on loading number of slots with different shapes into the rectangular patch of the micro-strip antenna.

The proposed micro-strip patch antenna has been designed and simulated using Microwave Office simulation package. The procedure for the design and simulation process can be summarized as follows.

Parameters selection and design: According to the analysis mentioned bofore, the antenna parameters can be shown as follows:

- $\quad$ Frequency of operation $=1.23 \mathrm{GHz}$

- Patch dimensions ( $\mathrm{L} \times \mathrm{W})=76 \times 121.125 \mathrm{~mm}$

- Substrate of thickness $(\mathrm{h})=4 \mathrm{~mm}(\sim 1.6 \%$ of the working wavelength)

- $\quad$ Relative permittivity $\left(\boldsymbol{\varepsilon}_{\Upsilon}\right)=2.62$

- Substrate size $=30.4 \times 45.6 \mathrm{~cm}$

- The probe feed is positioned at $(\mathrm{xf}=0, \mathrm{yf}=-2.13 \mathrm{~cm})$ with $(0.0)$ is the center of the patch

Regular slots configuration analysis: The geometrical parameters of the slot play an important role to control the behavior of the proposed antenna. The effect of these parameters on the antenna performance (return loss and input impedance) of the rectangular micro-strip antenna has been discussed on the basis of simulated results by MW office simulation package. The first step is to propose three antenna designs with 1-3 slots as shown in Fig. 2a-c simultaneously and their behavior simulated in order to study the antenna performance. In order to optimize, the numbers and positions of the regular slots, different number of slots have been proposed and simulated with different positions as shown in Fig. 3. The results of this simulation show that a good result was obtained by loading three slots of width $\mathrm{w}_{1}, \mathrm{w}_{2}$ and $w_{3}$ and lengths of $1_{1}-1_{3}$, respectively into the patch of the antenna as shown in Fig. 4. The determination of the optimum numbers and positions of the slots permit to go further in the optimization process, the next step is to estimate the optimum dimensions of each slot, this process can be started by testing the effect of changing the slot length $\left(1_{1}\right)$ for certain value of slot width $\left(\mathrm{w}_{1}\right)$ on the bandwidth, the results of this simulation is shown in Table 1, then testing the effect of changing $\left(w_{1}\right)$ for certain value of $\left(l_{1}\right)$, the results of this simulation is shown in Table 2. The analysis of these tests leads to estimate the optimum dimensions of each slot.

Irregular slots configuration analysis: In order to optimize, the slot shape of the patch antenna, slots with

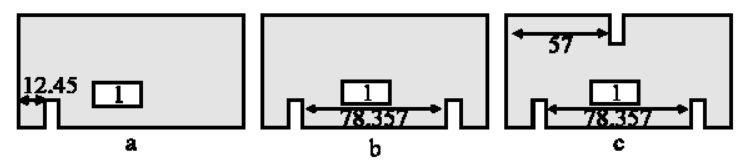

Fig. 2a-c: Antenna configurations with 1-3 slots

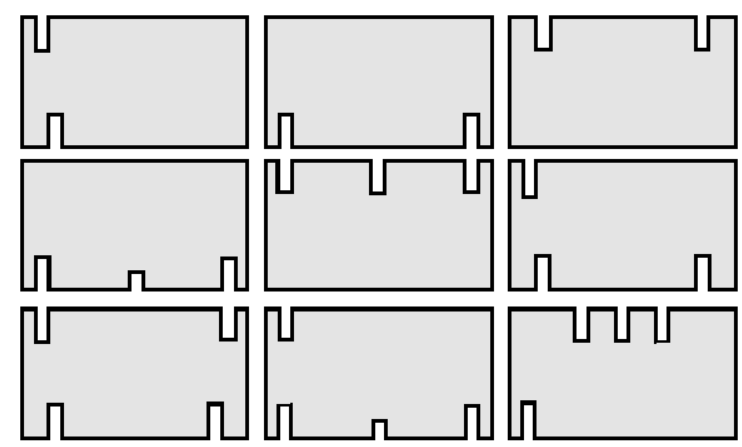

Fig. 3: Different number of slots with different positions to optimize the best bandwidth

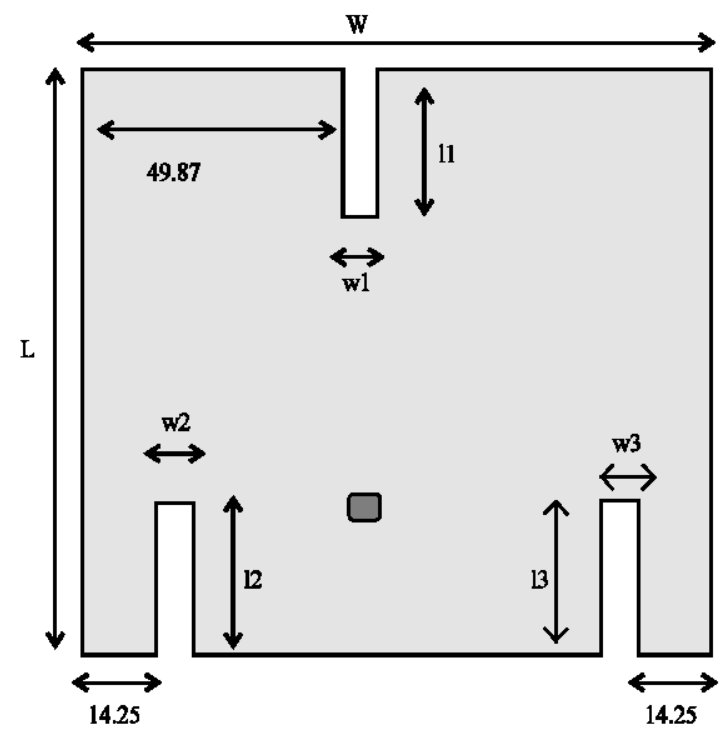

Fig. 4: Configuration of the proposed micro-strip antenna with three slots 
Table 1: Performance of the proposed antenna verses slots length $\left(l_{1}\right)$

\begin{tabular}{lccccccccccc}
\hline Antenna & $\mathrm{l}_{1}(\mathrm{~mm})$ & $\mathrm{l}_{2}(\mathrm{~mm})$ & $\mathrm{l}_{3}(\mathrm{~mm})$ & $\mathrm{w}_{1}(\mathrm{~mm})$ & $\mathrm{w}_{2}(\mathrm{~mm})$ & $\mathrm{w}_{3}(\mathrm{~mm})$ & $\mathrm{f}_{10}(\mathrm{GHz})$ & $\mathrm{f}_{\text {center }}(\mathrm{GHz})$ & $\mathrm{f}_{30}(\mathrm{GHz})$ & $\mathrm{BW}(\mathrm{GHz})$ & $\mathrm{BW}(\%)$ \\
\hline 1 & 19.000 & 19 & 19 & 7.125 & 7.125 & 7.125 & 1.19 & 1.230 & 1.27 & 0.140 & 11.0 \\
2 & 33.125 & 19 & 19 & 7.125 & 7.125 & 7.125 & 1.19 & 1.245 & 1.30 & 0.165 & 13.0 \\
3 & 47.500 & 19 & 19 & 7.125 & 7.125 & 7.125 & 1.19 & 1.250 & 1.31 & 0.180 & 14.5 \\
\hline
\end{tabular}

Table 2: Performance of the proposed antenna verses slots width $\left(\mathrm{w}_{1}\right)$

\begin{tabular}{lccccccccccc}
\hline Antenna & $\mathrm{l}_{1}(\mathrm{~mm})$ & $\mathrm{l}_{2}(\mathrm{~mm})$ & $\mathrm{l}_{3}(\mathrm{~mm})$ & $\mathrm{w}_{1}(\mathrm{~mm})$ & $\mathrm{w}_{2}(\mathrm{~mm})$ & $\mathrm{w}_{3}(\mathrm{~mm})$ & $\mathrm{f}_{10}(\mathrm{GHz})$ & $\mathrm{f}_{\text {center }}(\mathrm{GHz})$ & $\mathrm{f}_{80}(\mathrm{GHz})$ & $\mathrm{BW}(\mathrm{GHz})$ & $\mathrm{BW}(\%)$ \\
\hline 1 & 33.125 & 19 & 19 & 07.125 & 7.125 & 7.125 & 1.19 & 1.245 & 1.30 & 0.165 & 13 \\
2 & 33.125 & 19 & 19 & 14.250 & 7.125 & 7.125 & 1.18 & 1.240 & 1.30 & 0.180 & 14 \\
3 & 33.125 & 19 & 19 & 21.375 & 7.125 & 7.125 & 1.17 & 1.245 & 1.32 & $* * *$ & $* * *$ \\
\hline
\end{tabular}

** The two modes excited with separated resonance frequencies

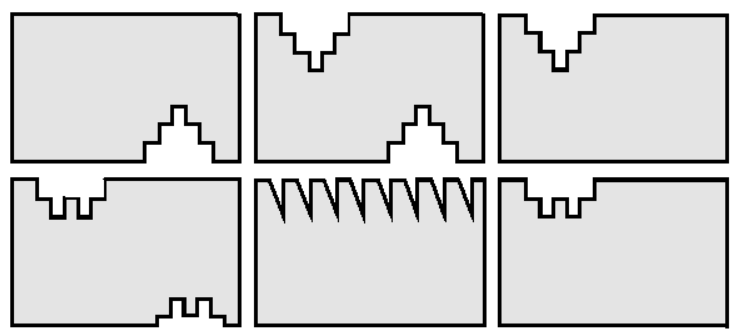

Fig. 5: Slots with different irregular shaped loaded to the patch of the antenna

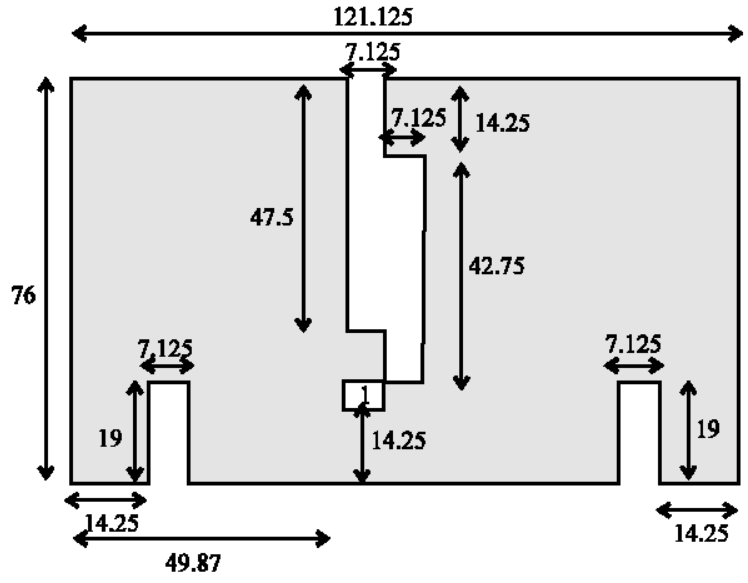

Fig. 6: Configuration of the antenna with irregular slots

different irregular shapes have been loaded to the rectangular patch of the antenna as shown in Fig. 5. The simulation results for different shapes configuration show that the proposed configuration shown in Fig. 6 gives the optimum performance; the proposed design gives bandwidth enhancement of about 5 times the bandwidth of the unslotted antenna.

\section{RESULTS AND DISCUSSION}

Analysis of the antenna with the configurations shown in Fig. 7. Figure 7 shows that adding slots into the patch of the antenna create a new resonance frequency and by adding more slots the two resonance regions

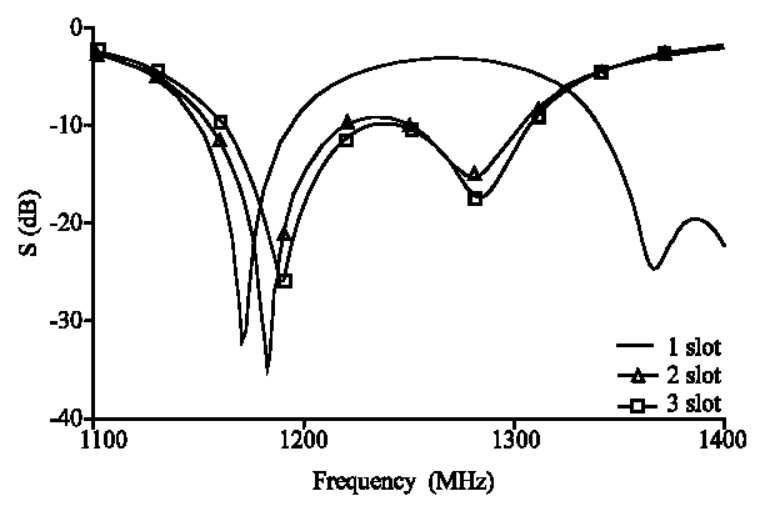

Fig. 7: Return loss for antennas with 1-3 slots

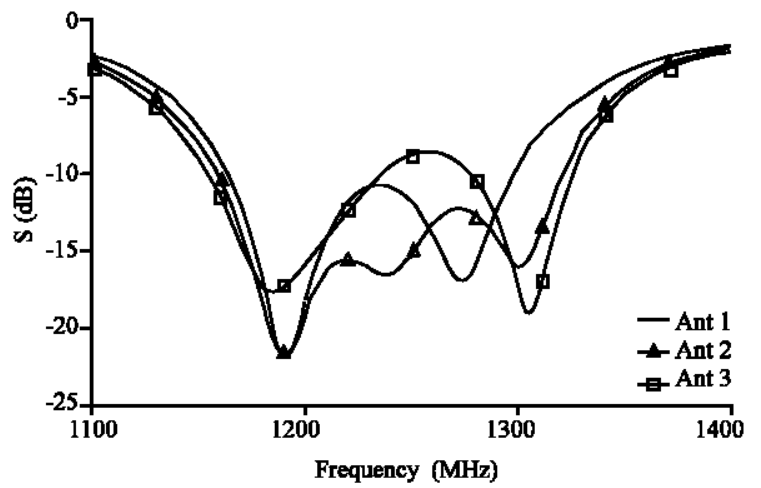

Fig. 8: Simulated return loss of the antennas parameters

come close to each other yielding an enhanced bandwidth. Analysis of the results shown in Table 1 and 2 , lead to estimate the optimum dimensions of the slots according to the designed central frequency and the required bandwidth.

Table 1 shows that the central frequency can be controlled by changing the slot length while Table 2 shows that the bandwidth can be controlled by changing the slot width.

Figure 8 and 9 show that maximum bandwidth which can be obtained for the structure shown in Fig. 4 is about $180 \mathrm{MHz}$ which represent a ratio of $14.5 \%$ of the central frequency. This ratio gives an enhancement ratio of about 


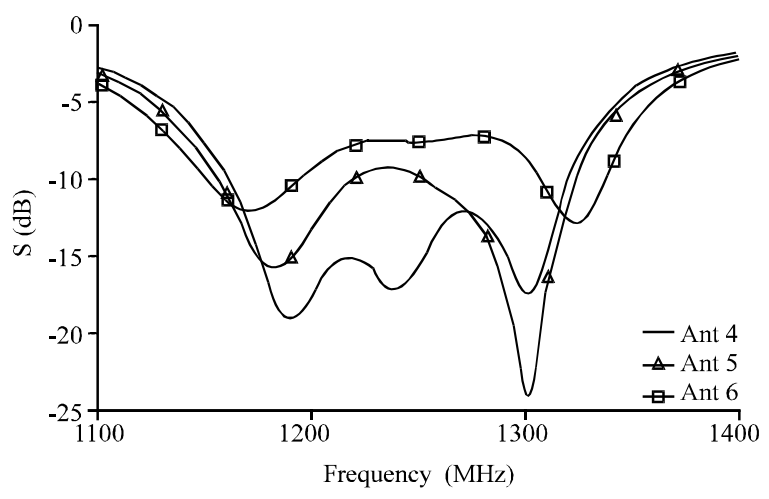

Fig. 9: Return loss of the antenna parameters

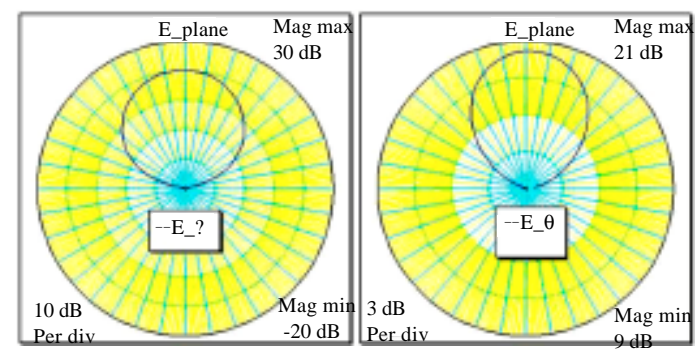

(a)

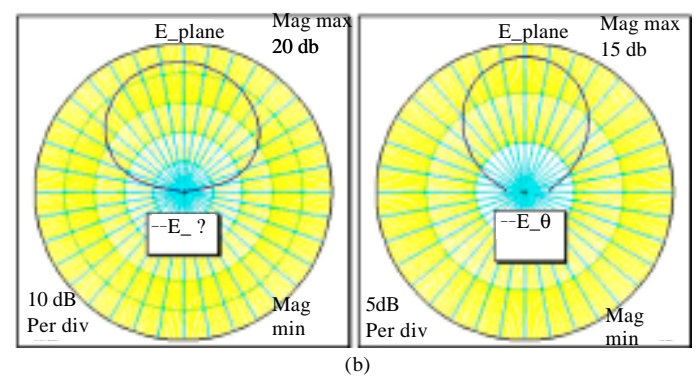

Fig. 10: E-plane and H-plane, a) For the unslotted antenna and b): For antenna 3 at the central frequency $1.25 \mathrm{GHz}$

4.5 compared with the unslotted micro-strip patch antenna bandwidth is $40 \mathrm{MHz}$ which represent a ratio of $3 \%$ of the central frequency. Figure 10 shows a reduction in the radiation beamwidth for the slotted micro-strip antenna (beamwidth $=71.1^{\circ}$ ) compared with that of unslotted antenna $\left(\right.$ beamwidth $=75.9^{\circ}$ ).

Figure 11 shows the bandwidth for the structure shown in Fig. 6 is approximately $200 \mathrm{MHz}$, this value represent a ratio of $16.2 \%$ of the central frequency which gives an enhancement of about 5 times compared with the unslotted micro-strip antenna. Figure 12 shows that there is no any deformation in the radiation pattern and there's only a reduction in the beamwidth of about $4.7 \%$ with a small shift in the E-plane from the zenith $\left(\varphi=0^{\circ}\right)$.

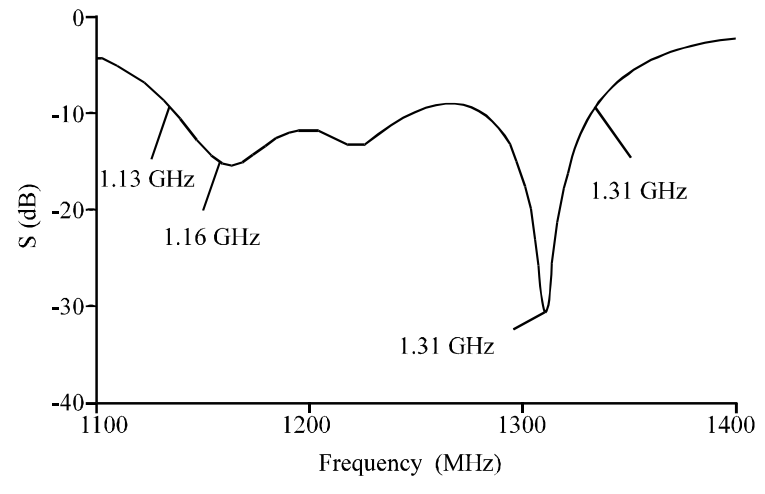

Fig. 11: Return loss of the proposed antenna with the structure
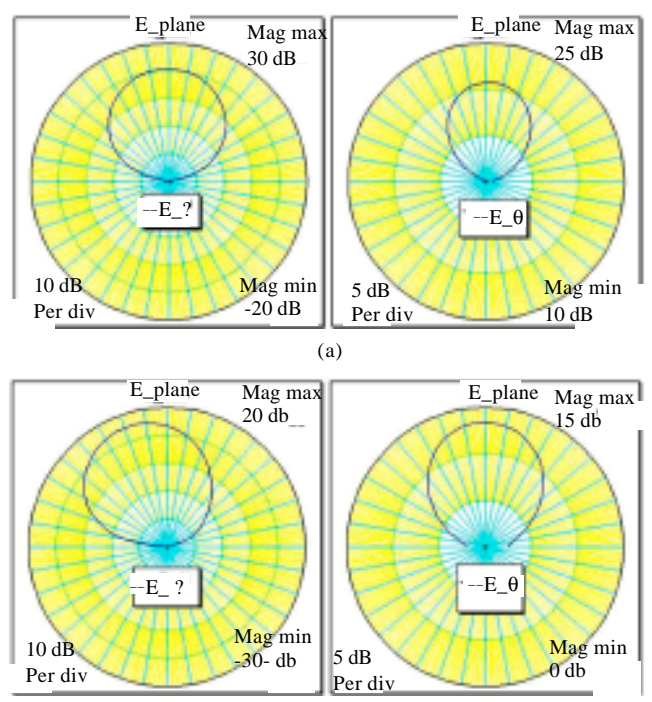

Fig. 12: E-plane and H-plane, a) For the unslotted antenna and b) For proposed bandwidth enhanced antenna at $1.23 \mathrm{Ghz}$

\section{CONCLUSION}

This study introduces the design and simulation of an enhanced micro-strip patch antenna. Different slots, positions and shapes of the slots has been proposed and examined. Simulation results show that an enhancement in the bandwidth of about 5 times $(16.2 \%$ of the central frequency) that of the unslotted micro-strip antenna can be achieved without any deformation in the radiation pattern for $\mathrm{h}=1.6 \%$ of the working wavelength. This results is better than that obtained by other researchers Jia-Yi and Wong (2000) presented a bandwidth of $4.6 \%$ of the central frequency for $\mathrm{h}=1 \%$ of the working wavelength and $\mathrm{Yu}$ and Zhang (2003) presented, a bandwidth of $6.8 \%$ of the central frequency for $\mathrm{h}=3.7 \%$ of the working wavelength. 


\section{REFERENCES}

Bahl, I.J. and P. Bhartia, 1980. Micro-strip Antennas. 1st Edn., Artech House Inc., USA., ISBN: 0-89006-098-3.

Godara, L.C., 2002. Handbook of Antennas in Wireless Communications. 1st Edn., CRC Press LLC, New York, ISBN: 0-8493-0124-6.

Grag, R., P. Bhartia, I. Bahl and A. Ittipiboon, 2001. Microstrip Antenna Design Handbook. 1st Edn., Artech House Inc., Boston, London, ISBN: 0-89006-513-6, pp: 845 .

Hammer, P., D. Van Bouchaute, D. Verschraeven and A. Van de Capelle, 1979. A model for calculating the radiation field of micro-strip antennas. Antennas Propagation IEEE Trans., 27: $267-270$.

Jia-Yi, S. and K.L. Wong, 2000. Slotted rectangular microstrip antenna for bandwidth enhancement. IEEE Trans. Antennas Propagation, 48: 1149-1152.
Kumar, G. and K.P. Ray, 2003. Broadband Micro-strip Antennas. 1st Edn., Artech House Inc., London, ISBN: 1-58053-244-6.

Mohammad, A.A., H. Subhi, A.K. Ahmad and S.M. Juma, 2006. Cavity model analysis of a rectangular microstrip antenna operating in TM03 mode. Proceedings of the Information and Communication Technologies, April 24-28, Damascus, pp: 2218-2223.

Xiao, S., Z. Shao, B.Z. Wang, M.T. Zhou and M. Fujise, 2006. Design of low profile micro-strip antenna with enhanced bandwidth and reduced size. Antennas Propagation IEEE Trans., 54: 1594-1599.

Yang, F., X.X. Zhang, X. Ye and Y. Rahmat-Samii, 2001. Wide-band E-shaped patch antennas for wireless communications. Antennas Propagation IEEE Trans., 49: 1094-1100.

$\mathrm{Yu}, \mathrm{A}$. and X. Zhang, 2003. A method to enhance the bandwidth of micro-strip antennas using a modified E-shaped patch. Proceedings of the Radio and Wireless Conference, Aug. 10-13, Boston, MA., pp: $261-264$. 